05

\title{
Мартенситные превращения сплавов на основе никелида титана с разными легирующими добавками
}

\author{
() Е.С. Марченко, Г.А. Байгонакова, В.Э. Гюнтер, А.А. Клопотов \\ Томский государственный университет, \\ 634050 Томск, Россия \\ e-mail: gat27@mail.ru
}

Поступило в Редакцию 19 сентября 2018 г.

В окончательной редакции 15 ноября 2019 г.

Принято к публикации 22 ноября 2019 г.

Приведены исследования мартенситных превращений сплавов на основе никелида титана марки ТН-10, легированных 1 at.\% V, Nb, Ag. Показано, что все легирующие элементы (Ag, Nb, V) вызывают рост внутренних упругих напряжений внутри кристаллической структуры $B 2$-фазы, что приводит к росту температуры начала прямого мартенситного превращения. Из выбранных легирующих элементов значительное влияние на эту температуру оказывает ванадий, сдвигая ее в область высоких значений на $\sim 45^{\circ} \mathrm{C}$. В сплавах с ванадием и серебром реализуется сложная последовательность мартенситных превращений $B 2 \rightarrow R \rightarrow B 19^{\prime}$, а с ниобием - простая $B 2 \rightarrow B 19^{\prime}$.

Ключевые слова: никелид титана, легирование, мартенситные превращения, $\mathrm{Ag}, \mathrm{Nb}, \mathrm{V}$, области когерентного рассеяния.

DOI: 10.21883/JTF.2020.05.49177.342-18

В настоящее время биосовместимые сплавы с памятью формы на основе TiNi марки TH-10, содержащие в своем составе, помимо титана и никеля, Мо и $\mathrm{Fe}$, успешно применяются в медицине в качестве имплантационного материала. Добавка Мо обеспечивает высокие стабильные технологические свойства конечного продукта и дает возможность регулировать характеристические температуры формоизменения вблизи температуры тела человека. Железо является эффективным при легировании до 0.5 at.\%, когда наблюдается сочетание высоких прочностных и пластических свойств. Изменение основного состава сплава путем введения различных легирующих добавок меняет структурно-фазовое состояние, что позволяет получать новые материалы с улучшенными свойствами [1]. Выбор легирующего элемента определяет внутреннюю структуру материала, от которой зависят свойства сплава. В настоящей работе в качестве легирующих элементов для сплавов марки ТН-10 были выбраны ванадий, ниобий и серебро, которые являются примесями замещения по классификатору легирующих элементов и примесей в титане, и влияют на температуры мартенситных превращений (МП) [2].

Существует ряд работ, направленных на исследование МП в тройных сплавах $\mathrm{Ti}-\mathrm{Ni}-\mathrm{V}, \mathrm{Ti}-\mathrm{Ni}-\mathrm{Nb}$, $\mathrm{Ti}-\mathrm{Ni}-\mathrm{Ag}$. Так, в [3] особое внимание уделено расслоению высокотемпературной $B 2$-фазы в сплавах TiNiV $\left(C_{V}=4-8\right.$ at.\%) на 2 изоморфных твердых раствора при переходе $B 2 \rightarrow R \rightarrow B 19^{\prime}$, сопровождающемуся снижением температур $M_{S}, M_{f}$ и уширением температурного гистерезиса. Аналогичное влияние на ширину петли гистерезиса выявлено в системе $\mathrm{Ti}-\mathrm{Ni}-\mathrm{Nb}$ $\left(C_{\mathrm{Nb}}=3-12\right.$ at.\%), где в отличие от TiNiV реализуется одностадийное $B 2 \rightarrow B 19^{\prime}$ МП [4,5]. В [6,7] рассмат- риваются МП сплавов TiNiAg, при этом в сплавах с низкой концентрацией серебра $\left(C_{\mathrm{Ag}}=0.6-0.9\right.$ at.\%) существует МП $B 2 \rightarrow B 19^{\prime}$ и легирование понижает температуру $M_{S}$, в сплавах с более высоким значением легирующего компонента (начиная с 1 at.\% Ag) последовательность МП переходит в двустадийный МП $B 2 \rightarrow R \rightarrow B 19^{\prime}$ и сопровождается смещением фазового перехода в высокотемпературную область.

Особенности развития термоупругих МП в многокомпонентных медицинских сплавах марки ТН-10, легированных V, $\mathrm{Nb}$ и $\mathrm{Ag}$, не исследованы. Поэтому при выяснении природы МП в многокомпонентных сплавах на основе TiNi важными являются исследования, которые позволят провести сравнительный анализ влияния разных элементов на термоупругие МП. Исходя из вышесказанного, целью настоящей работы является исследование влияния $\mathrm{V}, \mathrm{Nb}, \mathrm{Ag}$ на характеристики МП медицинских многокомпонентных сплавов марки ТН-10.

Сплав марки ТН-10 ( $\left.\mathrm{Ti}_{50} \mathrm{Ni}_{49.5} \mathrm{Mo}_{0.3} \mathrm{Fe}_{0.2}\right)$ был выбран эталонным. В качестве легирующих элементов были поочередно взяты $\mathrm{V}, \mathrm{Nb}, \mathrm{Ag}$ с одинаковой концентрацией (1 at.\%), добавленные в шихту вместо никеля по схеме легирования $\mathrm{Ti}_{50} \mathrm{Ni}_{49.5-\mathrm{X}} \mathrm{Mo}_{0.3} \mathrm{X}(\mathrm{X}=1 \mathrm{at} . \% \mathrm{~V}, \mathrm{Nb}, \mathrm{Ag})$. В индукционной печи ИСВ-0.004 ПИ М1 в атмосфере инертного газа аргона были выплавлены три слитка c 1 at.\% V, 1 at.\% Nb и 1 at.\% Ag. Из полученных слитков без дополнительных термомеханических обработок были вырезаны образцы для исследований. Измерение температурной зависимости удельного электросопротивления $\rho(T)$ осуществляли потенциометрическим методом. Изучение фазового состава и структурных параметров образцов проводилось на дифрактометре XRD-6000 в $\mathrm{Cu} K_{\alpha}$-излучении. Изображения поверхности получены 
Таблица 1. Данные рентгенографического исследования В2-фазы

\begin{tabular}{l|c|c|c}
\hline \multicolumn{1}{c|}{ Сплав } & $\begin{array}{c}\text { Параметры } \\
\text { решетки, } \AA\end{array}$ & $\begin{array}{c}\text { Размер } \\
\text { ОКР, nm }\end{array}$ & $\Delta d / d \cdot 10^{-3}$ \\
\hline TH-10 & $a=3.0148$ & 56 & 0.54 \\
TH-10+1 at.\% Ag & $a=3.0111$ & 28 & 1.44 \\
TH-10+1 at.\% Nb & $a=3.0120$ & 22 & 1.91 \\
TH-10+1 at.\% V & $a=3.0130$ & 19 & 2.47
\end{tabular}

на оптическом микроскопе с использованием микроанализатора элементного состава.

Рентгенофазный анализ показал, что во всех сплавах при комнатной температуре формируется многофазная смесь: интерметаллид TiNi в различных модификациях и соединение $\mathrm{Ti}_{2} \mathrm{Ni}$. В сплавах c $\mathrm{V}$ и $\mathrm{Ag}$ интерметаллид TiNi присутствует в виде трех кристаллических структур: $B 2, R$ и $B 19^{\prime}$, а в сплавах с Nb - в двух: $B 2, B 19^{\prime}$. Это отражает последовательность МП $\left(B 2 \rightarrow R \rightarrow B 19^{\prime}\right.$ или $\left.B 2 \rightarrow B 19^{\prime}\right)$ и хорошо согласуется с данными $\rho(T)$. Удельное электросопротивление мартенсита $B 19^{\prime}$ более низкое, чем высокотемпературной B2-фазы. В сплавах на основе TiNi рост величины $\rho(T)$ при МП аустенитмартенсит определяет наличие $R$-фазы [8]. Дифракционных отражений, свидетельствующих о формировании дополнительных фаз с $\mathrm{Nb}$ и $\mathrm{V}$, нет. Отличительной особенностью сплавов, легированных 1 at.\% Ag, является наличие аморфной и кристаллической фазы $\mathrm{Ag} \mathrm{c}$ ГЦК-решеткой и параметром $a_{\mathrm{Ag}}=4.0845 \AA$. В сплавах с 1 at.\% V в твердом растворе B2-фазы TiNi растворяется все введенное в шихту количество V; в сплавах c 1 at.\% $\mathrm{Nb}$ и $\mathrm{Ag}$ - не более 0.65 at.\%. Это подтверждают данные локального энергодисперсионного микроанализа.

Качественный и количественный фазовый состав исследуемых сплавов приведен в табл. 1, где $a-$ параметр решетки, ОКР - кристаллические области когерентного рассеяния и $\Delta d / d-$ внутренние упругие напряжения второго рода внутри кристаллической решетки $B 2$-фазы.

Контроль характеристических температур МП сплавов с памятью формы является важным для оценки влияния легирующих элементов на свойства и применимость медицинских материалов [1-9]. Температуры МП в сплавах на основе TiNi определяются следующими основными факторами: химическим составом матрицы (соотношением титана и никеля), содержанием легирующих элементов и образованных с их участием вторичных фаз, внутренним напряжением матрицы, размером зерен и особенностями электронной структуры сплавов.

На рис. 1 и в табл. 2 приведены диаграммы МП и значения характеристических температур МП $\left(T_{R}, M_{S}, M_{f}\right)$ для исходного сплава (ТН-10) и сплавов, легированных 1 at.\% (V, Nb, Ag). Экспериментальные результаты показывают, что легирование сплава ТН-10 любым из рассматриваемых элементов приводит к сме-

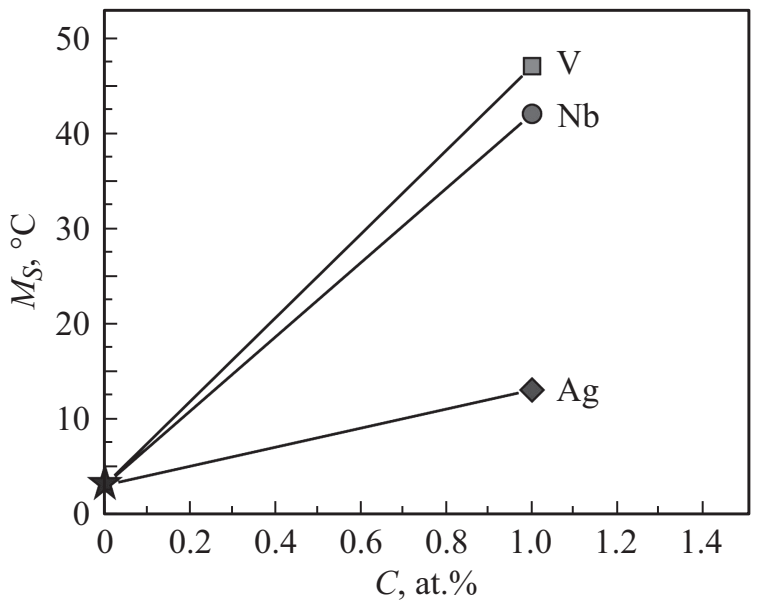

Рис. 1. Диаграмма температуры начала МП $M_{S}$ для исходного сплава и сплавов, легированных 1 at.\% (V, $\mathrm{Nb}, \mathrm{Ag})$.

щению температуры начала прямого МП $M_{S}$ в область высоких температур, снижая устойчивость структуры аустенитной В2-фазы.

Введение в состав сплава легирующих элементов изменяет состав матричного сплава $\mathrm{TiNi}$, меняя соотношение $\mathrm{Ti}$ и $\mathrm{Ni}$ в зависимости от типа выпавших вторичных фаз и их объемных долей. В соответствие с этим температура $M_{S}$ понижается при избытке никеля в матрице или повышается при избытке титана. Кроме того, легирующие элементы создают в матрице высоконапряженные области в процессе образования кристаллов мартенситной фазы, которые в соответствии с уравнением равновесия Клапейрона-Клаузиуса приводят к смещению температуры фазового перехода в область более высоких температур:

$$
\Delta \sigma=k \Delta T,
$$

где $\Delta \sigma-$ изменение внутренних напряжений, $k-$ коэффициент пропорциональности, $\Delta T-$ изменение температуры равновесия [9].

Самое существенное влияние на температуру начала МП оказывает ванадий, он приводит к сдвигу фазового перехода $B 2 \rightarrow R \rightarrow B 19^{\prime}$ в область высоких температур на $\sim 45^{\circ} \mathrm{C}$. Причиной являются высокие значения внутренних упругих напряжений внутри кристаллической решетки B2-фазы среди исследуемых сплавов (табл. 1).

Чтобы понять, каким образом сформировавшаяся внутренняя структура сплава после легирования влияет на температуры МП, рассмотрим оптикомикроскопические исследования (рис. 2). Зерна представляют собой блоки (области когерентного рассеяния, (ОКР)) с протяженными дефектами - границами зерен. Поэтому величина ОКР зависит от размеров зерен и протяженности их границ. Сплавы с большим размером зерен имеют протяженные редкие границы зерен и соответственно большие области ОКР и низкие значения внутренних напряжений в матрице от этих 
Таблица 2. Значения характеристических температур МП для исходного сплава и сплавов, легированных $1 \mathrm{at} . \%$ (V, Nb, Ag)

\begin{tabular}{c|c|c|c|c}
\hline Характеристические температуры МП & 0 at.\% & 1 at.\% Ag & 1 at.\% Nb & 1 at.\% V \\
\hline$T_{R},{ }^{\circ} \mathrm{C}$ & 21 & 29 & - & 67 \\
$M_{S},{ }^{\circ} \mathrm{C}$ & 3 & 13 & 42 & 47 \\
$M_{f},{ }^{\circ} \mathrm{C}$ & -35 & -29 & 2 & 31 \\
$\left(M_{S}-M_{f}\right),{ }^{\circ} \mathrm{C}$ & 38 & 42 & 40 & 16 \\
Тип МП & $B 2 \rightarrow R \rightarrow B 19^{\prime}$ & $B 2 \rightarrow R \rightarrow B 19^{\prime}$ & $B 2 \rightarrow B 19^{\prime}$ & $B 2 \rightarrow R \rightarrow B 19^{\prime}$
\end{tabular}
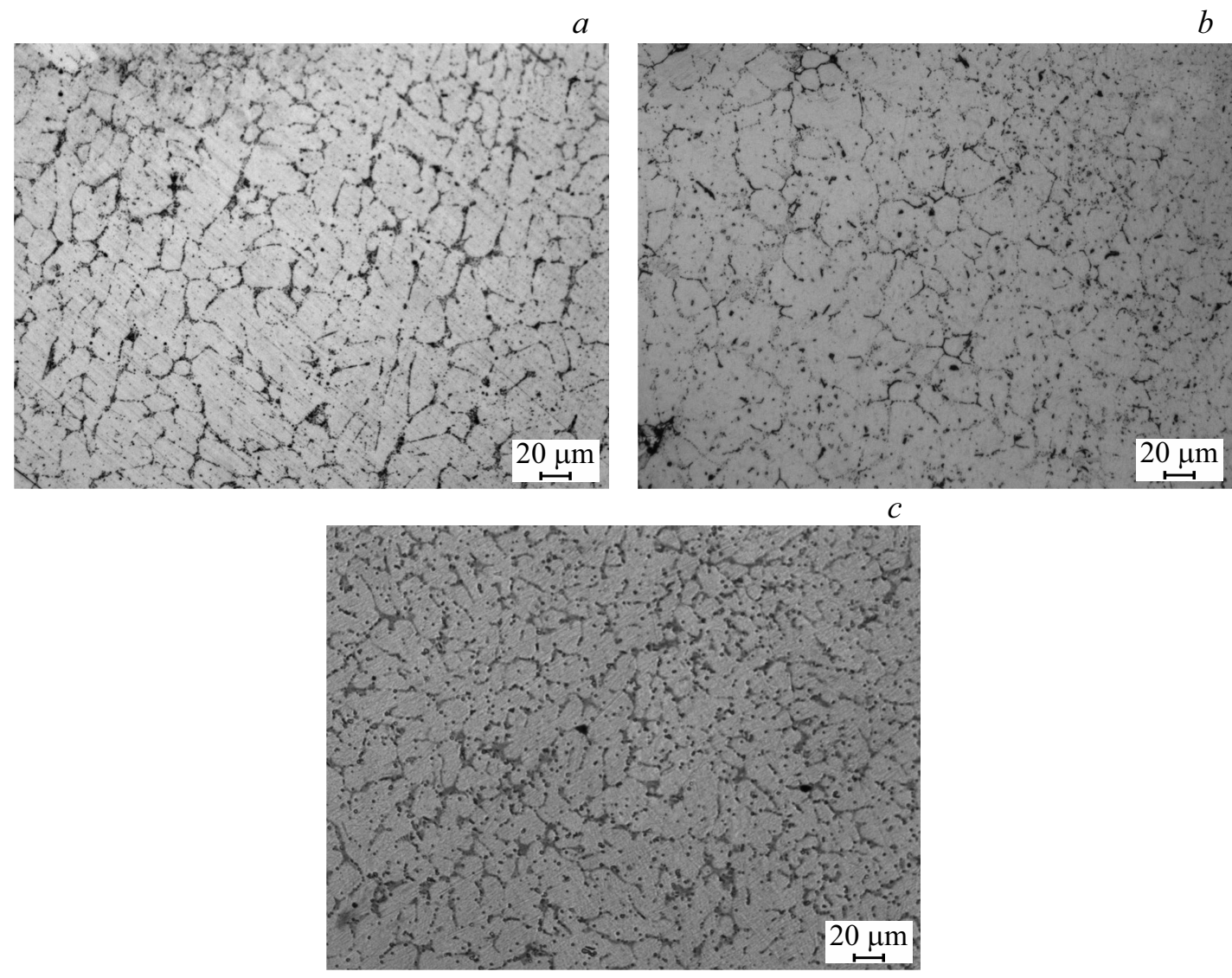

Рис. 2. Оптическая микроскопия сплавов марки ТН-10, легированных 1 at.\%: $a-\mathrm{Ag}, b-\mathrm{Nb}, c-\mathrm{V}$.

границ. По микрофотографиям был определен средний размер зерен во всех сплавах, который зависит от типа легирующего элемента. В сплавах с серебром - 20 и более $\mu \mathrm{m} ;$ с ниобием $-12-16 \mu \mathrm{m}$; с ванадием $8-12 \mu \mathrm{m}$. Полученные данные хорошо коррелируют с изменением кристаллических областей когерентного рассеяния (табл. 1). Так, на примере сплава с ванадием с минимальным размером зерен и частыми границами значения ОКР составляют $19 \mathrm{~nm}$ и напряжений $2.47 \cdot 10^{-3}$, которые, согласно уравнению Клапейрона-Клаузиуса, вызывают фазовый переход раньше, чем в исходном сплаве на $\sim 45^{\circ} \mathrm{C}$.

Таким образом, показана чувствительность характеристических температур фазовых переходов к изменению состава сплава путем введения легирующих элементов. Все легирующие элементы $(\mathrm{Ag}, \mathrm{Nb}, \mathrm{V})$ вызывают рост внутренних упругих напряжений внутри кристаллической структуры $B 2$-фазы и в соответствии с уравнением Клапейрона-Клаузиуса приводят к росту температуры $M_{S}$. Самое существенное влияние на температуру начала МП оказывает ванадий, он приводит к сдвигу фазового перехода $B 2 \rightarrow R \rightarrow B 19^{\prime}$ в область высоких температур на $\sim 45^{\circ} \mathrm{C}$. Показано, что сплавы с серебром имеют зерна большого размера $(\geq 20 \mu \mathrm{m})$ с протяженными редкими границами; такая макроструктура соответствует большим значениям ОКР и низким внутренним упругим напряжениям второго рода внутри кристаллической решетки $B 2$-фазы.

\section{Конфликт интересов}

Авторы заявляют, что у них нет конфликта интересов. 


\section{Список литературы}

[1] Gunther V.E. // KnE. Mater. Sci. 2017. S. 1. P. 1-9.

[2] Гуляев А.П. Металловедение. М.: Металлургия, 1986. 272 с.

[3] Lin H.C., Yang C.H., Lin M.C., Lin C.S., Lin K.M., Changc L.S. // J. Alloys and Compounds. 2008. Vol. 449. P. $119-124$.

[4] He X.M., Rong L.J., Yan D.S., Li Y.Y. // Mater. Sci. Engineer. 2004. Vol. 38. N 32. P. 193-197.

[5] Abramov V.Ya., Aleksandrova N.M., Borovkov D.V., Khmelevskaya I.Yu. // Mater. Sci. Engineer. 2006. Vol. 438440. P. 553-557.

[6] Su-Jin Chun, Jung-pil Noh, Jong-taek Yeom, Jae-il Kim, Taehyun Nam // Intermetallics. 2014. Vol. 46. P. 91-96.

[7] Alvares da Silva G., Otubo J. // MATEC Web Conf. 2015. Vol. 33. P. 03009.

[8] Байгонакова Г.А., Марченко Е.С., Гюнтер В.Э. // Письма в ЖТФ. 2017. Т. 43. Вып. 20. С. 61-68.

[9] Марченко Е.С., Байгонакова Г.А., Гюнтер В.Э., Чекалкин Т.Л. // Деформация и разрушение материалов. 2016. № 8. C. 14-17. 